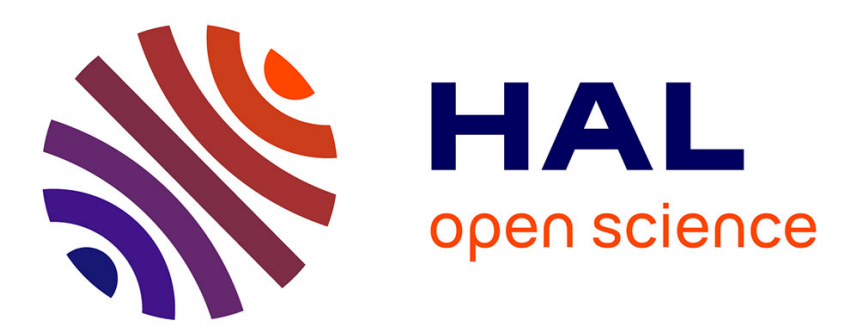

\title{
Model Clouds over Oceans as Seen from Space: Comparison with HIRS/2 and MSU Radiances
}

\author{
F. Chevallier, P. Bauer, G. Kelly, C. Jakob, T. Mcnally
}

\section{To cite this version:}

F. Chevallier, P. Bauer, G. Kelly, C. Jakob, T. Mcnally. Model Clouds over Oceans as Seen from Space: Comparison with HIRS/2 and MSU Radiances. Journal of Climate, 2001, 14 (21), pp.42164229. 10.1175/1520-0442(2001)0142.0.CO;2 . hal-02947897

\section{HAL Id: hal-02947897 https://hal.science/hal-02947897}

Submitted on 8 Feb 2021

HAL is a multi-disciplinary open access archive for the deposit and dissemination of scientific research documents, whether they are published or not. The documents may come from teaching and research institutions in France or abroad, or from public or private research centers.
L'archive ouverte pluridisciplinaire HAL, est destinée au dépôt et à la diffusion de documents scientifiques de niveau recherche, publiés ou non, émanant des établissements d'enseignement et de recherche français ou étrangers, des laboratoires publics ou privés. 


\title{
Model Clouds over Oceans as Seen from Space: Comparison with HIRS/2 and MSU Radiances
}

\author{
F. Chevallier, P. Bauer, G. Kelly, C. Jakob, and T. McNally \\ European Centre for Medium-Range Weather Forecasts, Reading, Berkshire, United Kingdom
}

(Manuscript received 13 February 2001, in final form 30 April 2001)

\section{ABSTRACT}

Radiation observations are a key element in the evaluation of the 40-yr reanalysis at the European Centre for Medium-Range Weather Forecasts. This paper uses the High-Resolution Infrared Radiation Sounder/2 (HIRS/ 2) and Microwave Sounding Unit (MSU) observations on board the National Oceanic and Atmospheric Administration satellites, to assess the characteristics of the cloud fields produced by the forecasting system over midlatitude and tropical oceans. Infrared and microwave radiation have different sensitivities to clouds and are therefore complementary. Observed and model-generated radiances, as well as HIRS/2-derived cloud parameters, are compared.

The model clouds are shown to be well distributed, with realistic seasonal cycles. However, deficiencies are identified and discussed: the cloud radiative impact may be too low in the midlatitudes, the frequency of occurrence of high clouds is overestimated in the intertropical convergence zone, and the stratocumulus off the west coast of the continents is underestimated. The methods described here provide a framework for assessing the impact of forthcoming improvements to the cloud scheme.

\section{Introduction}

Clouds have a high variability in time and space. As large reservoirs of latent heat, they exert a major influence on the atmospheric energy balance. Also the atmospheric heating rates are strongly affected by the interaction of clouds with visible and infrared electromagnetic waves. However, through emission, absorption, reflection, and scattering processes, this interaction itself makes it difficult to observe clouds from a distance. For satellite measurements, complex algorithms are used either to retrieve the cloud information (e.g., Rossow and Schiffer 1991; Wylie et al. 1994; Stubenrauch et al. 1999; Baum et al. 2000) or to remove it in order to get cloud-clear products (e.g., McMillin and Dean 1982; Munro et al. 2000).

Cloud-affected narrowband and broadband spectral satellite measurements, as well as derived cloud variables, form valuable datasets for atmospheric studies. They have also become an essential part of the validation of atmospheric general circulation models (Le Treut and Li 1988; Morcrette 1991a; Shah and Rind 1995; Bony et al. 1997). As such, the observations from the Television Infrared Observational Satellite (TIROSN) Operational Vertical Sounder (TOVS) instruments

Corresponding author address: F. Chevallier, European Centre for Medium-Range Weather Forecasts, Shinfield Park, Reading, Berkshire RG29AX, United Kingdom.

E-mail: f.chevallier@ecmwf.int on board the National Oceanic and Atmospheric Administration's (NOAA) polar-orbiting satellites are an important part of the evaluation of the analysis/forecast system at the European Centre for Medium-Range Weather Forecasts (ECMWF). This is particularly true for the 40-yr (from 1957 onward) ECMWF reanalysis (ERA) that is being produced (ERA-40; Simmons and Gibson 2000).

In this paper, the 6-h forecast from a test production of ERA-40 is compared with the High-Resolution Infrared Radiation Sounder/2 (HIRS/2) and Microwave Sounding Unit (MSU) data from the TOVS over midlatitude and tropical oceans $\left(60^{\circ} \mathrm{S}-60^{\circ} \mathrm{N}\right)$. The data and the model are described in section 2. Model-equivalent infrared and microwave radiances are computed from the model variables using a forward radiation scheme detailed in section 3. For MSU, the model-observation comparison is made for the radiances only. The cloud variables retrieved from HIRS with the $\mathrm{CO}_{2}$-slicing technique described by Wylie et al. (1994) are useful for comparisons with the model. They implicitly contain part of the multispectral information of the radiometer. However these cloud variables are to be understood as radiatively effective quantities, in the sense that they are defined as seen from the satellite. Therefore in the present study, the $\mathrm{CO}_{2}$-slicing technique of Wylie et al. (1994) and Wylie and Menzel (1999) is used to derive cloud-top pressure and effective cloud emissivity from the observed HIRS brightness temperatures as well as 
(a) DJF, Mid-latitudes

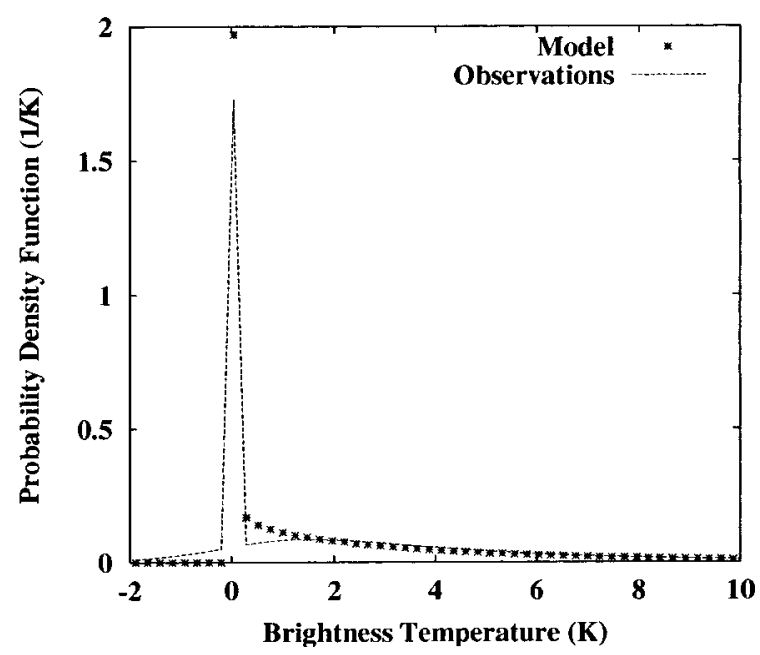

(c) JJA, Mid-latitudes

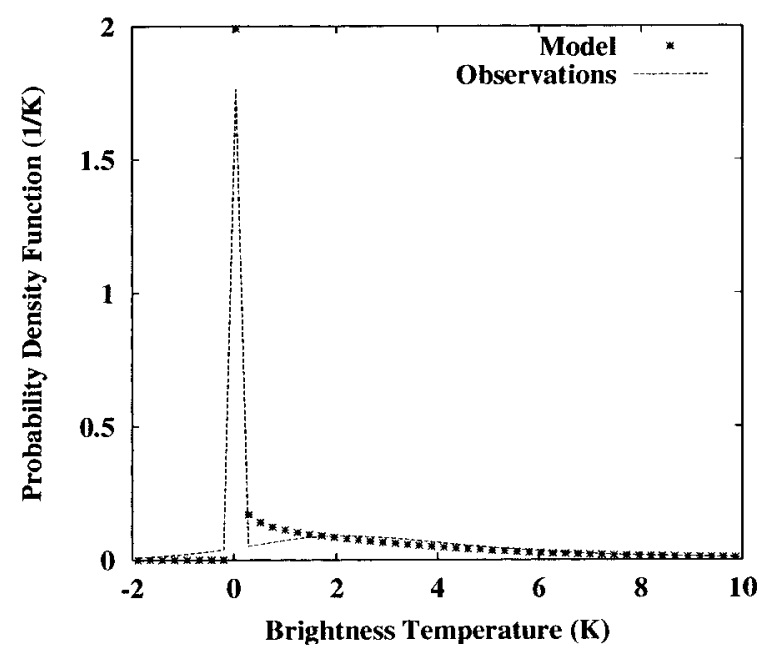

(b) DJF, Tropical latitudes

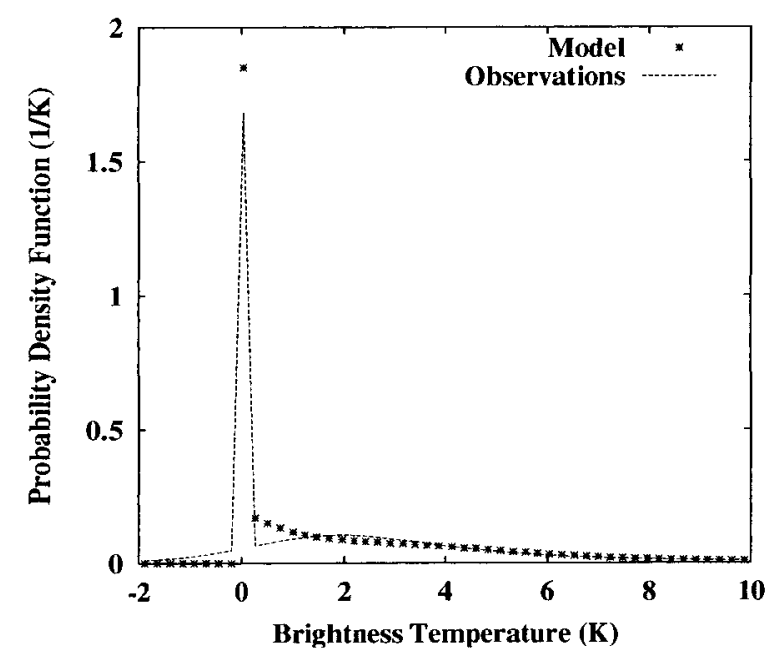

(d) JJA, Tropical latitudes

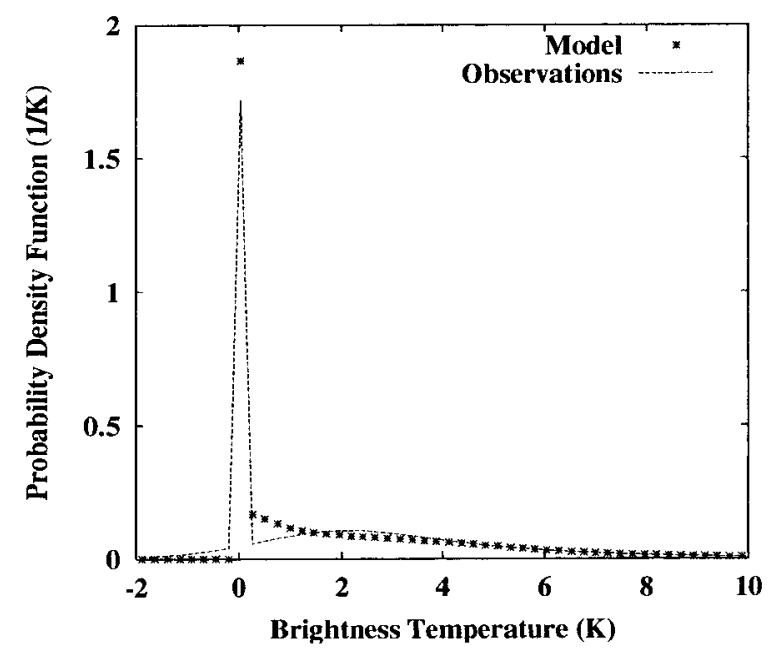

FIG. 1. Histograms of the difference between MSU-1 cloud-affected brightness temperature, either from the model or from the observation, and the model clear-sky MSU-1 brightness temperature [i.e., the difference between $\left(\mathrm{Tb}_{\text {Model }}^{\text {Full }}-\mathrm{Tb}_{\text {Model }}^{\mathrm{Clr}}\right)$ and $\left.\left(\mathrm{Tb}_{\mathrm{Obs}}^{\mathrm{Full}}-\mathrm{Tb}_{\text {Model }}^{\mathrm{Clr}}\right)\right]$.

from the model-derived ones. The method is detailed in section 3. The MSU radiance comparison is presented in section 4. The HIRS radiance and the HIRS-derived cloud variable comparisons are shown in section 5 . The conclusions are outlined in section 6 .

\section{The data}

\section{a. The TOVS data}

The MSU radiometer of TOVS comprises four channels for making passive measurements in the 5.5-mmwavelength oxygen region. Their weighting functions respectively peak at the surface and at 700, 300, and 90
hPa. An MSU spot has a typical circular shape of 54.7$\mathrm{km}$ radius at nadir and an elliptic shape of axis 323.1 and $178.8 \mathrm{~km}$ at the end of the scan (Kidwell 1998).

The HIRS/2 instrument of TOVS measures radiation in 20 channels covering both the longwave and the shortwave parts of the spectrum. The ground instantaneous field of view is typically a circle of $17.4-\mathrm{km}$ diameter at nadir. At the end of the scan, the ground field of view is $58.5-\mathrm{km}$ cross track by $29.9-\mathrm{km}$ along track (Kidwell 1998).

The raw radiances for HIRS and MSU are taken here from the NOAA-9 and NOAA-10 satellites. Both of them operate in a near-polar, sun-synchronous orbit, with 
(a) DJF, Observations

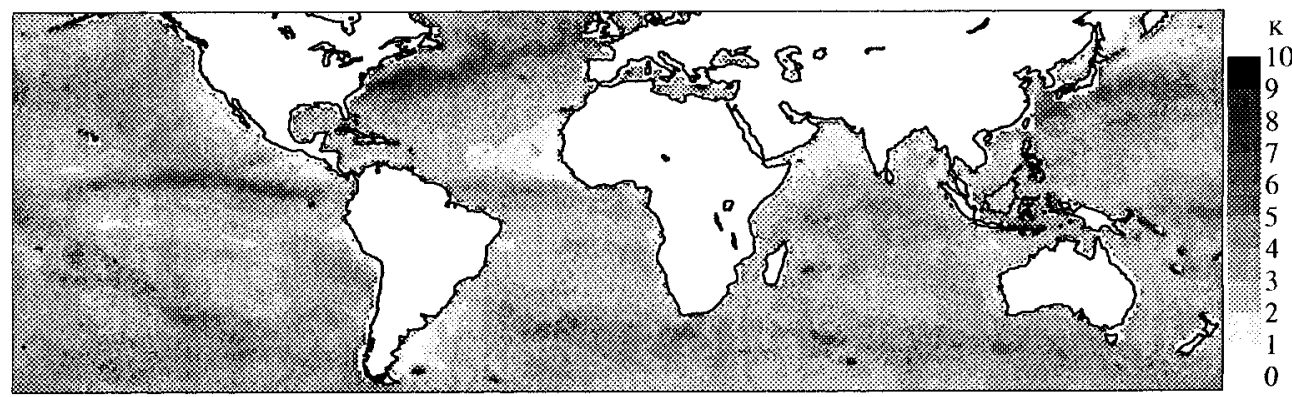

(b) DJF, Model

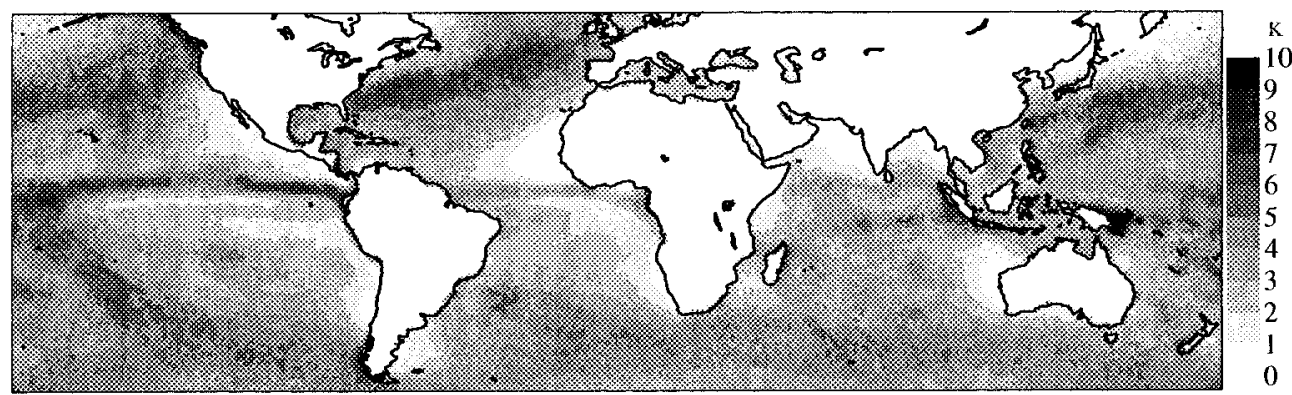

(c) JJA, Observations

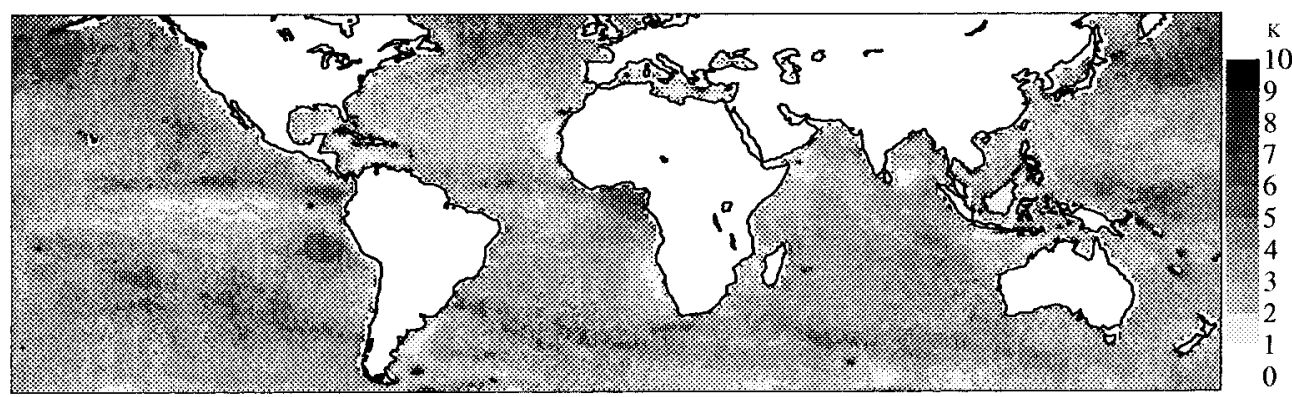

(d) JJA, Model

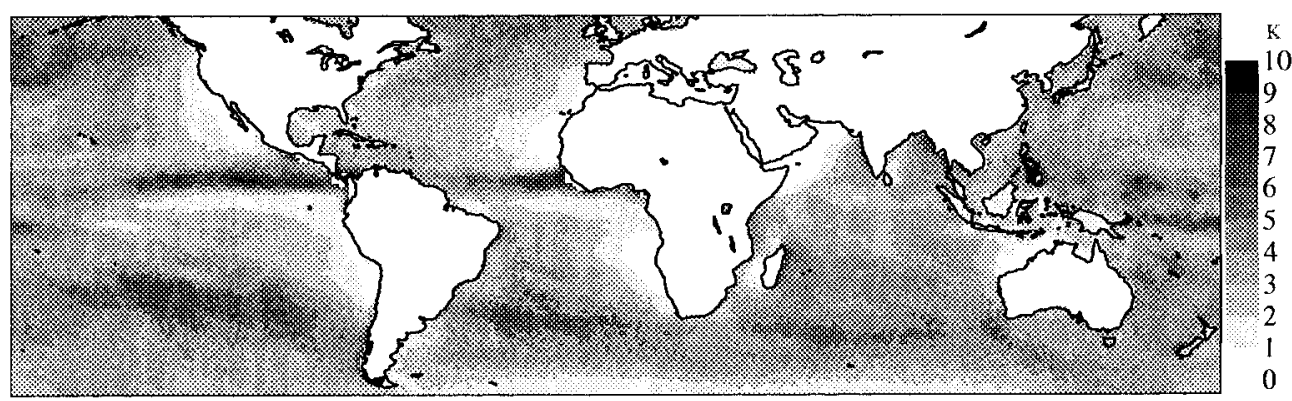

FIG. 2. Observed and simulated MSU channel 1 minus model clear-sky MSU channel 1 in the boreal winter (DJF) and summer (JJA) seasons. 
TABLE 1. Launch date and approximate time of the ascending node (northbound equator crossing) in LST for NOAA-9 and NOAA-10 when the satellites were launched. Because of the drift in the satellites' orbit over time, the equator crossing time for NOAA-9 is close to $1500 \mathrm{LST}$ for the period studied (Price 1991).

\begin{tabular}{lcc}
\hline \hline \multicolumn{1}{c}{ Satellite } & NOAA-9 & NOAA-10 \\
\hline Launch & Dec 1984 & Sep 1986 \\
Ascending node & 1420 & 1930 \\
\hline
\end{tabular}

about 14 orbits per day. As reported in Table 1, they cross the equator at different times and therefore provide some information about the diurnal cycle of the earthatmosphere system when combined together. Because of the high volume of data, only one HIRS spot over four is processed here, irrespective of scan angle. All MSU spots are used.

Various biases affect the brightness temperatures throughout the life of an instrument. The data used here are bias corrected with the ECMWF operational method described by Harris and Kelly (2001). The computed biases can reach several kelvins in some channels. In the framework of the $\mathrm{CO}_{2}$-slicing method described below, these corrections were shown to improve the consistency between the different channels.

\section{b. The model fields}

The model data come from a test run of the ECMWF 40 -yr reanalysis. The forthcoming final version of the reanalysis will differ only by minor improvements from the system used in the present test run.

The assimilation system relies on the three-dimensional variational scheme described by Courtier et al. (1998), Rabier et al. (1998), and Andersson et al. (1998). It includes the TOVS raw radiances that are diagnosed as not affected by clouds. Also, with impact on the hydrological cycle, radiosonde and surface data, cloudwind product from geostationary satellites, scatterometer winds, column water vapor, and surface winds from Special Sensor Microwave Imager (SSM/I, from August 1987) are assimilated. Analyses are performed at $0000,0600,1200$, and 1800 UTC.

The forecast model is a global spectral $T_{L} 159 \mathrm{~L} 60$ model. It includes a semi-Lagrangian advection scheme together with a linear Gaussian grid (Hortal 1999). The reduced horizontal grid corresponds to a regular grid size of about $125 \mathrm{~km}$ from the equator to the Poles. In the vertical, a hybrid coordinate of 60 levels between the surface and the top of the atmosphere is used by the global spectral forecast model. The physics package is an improved version of that described by Gregory et al. (2000). In particular, the prognostic cloud scheme is a revised version of that defined by Tiedtke (1993), with details of the revisions described in Jakob $(1994,2000)$, Jakob and Klein (2000), and Jakob et al. (2000). The broadband radiation scheme includes the Rapid Radiative Transfer Model (Mlawer et al. 1997) for the in- frared and the Fouquart and Bonnel (1980) scheme (with four spectral bands) for the shortwave. The surface scheme is based on the new tiled treatment described by van den Hurk et al. (2000).

In the following, 6-h forecasts at 0000, 0600, 1200, and 1800 UTC are compared with the TOVS data in the 6-h window that is centered around the forecast time. Model data are interpolated at observation points and at observation times. Because the resolution of the observations and that of the model differ, emphasis is put here on seasonal statistics rather than on instantaneous comparisons. Both boreal winter 1986/87 [DecemberFebruary (DJF)] and summer 1987 [June-August (JJA)] are considered.

\section{Comparing model and satellite data}

\section{a. Clear-sky radiative transfer}

For a stratified cloudless atmosphere in local thermodynamical equilibrium, the top-of-the-atmosphere upwelling radiance at frequency $\nu$ can be written:

$$
\begin{aligned}
L_{\nu}^{\operatorname{Clr}}(\theta)= & \epsilon_{\nu}(\theta) \tau_{\nu}^{\uparrow}\left(P_{0}, \theta\right) B_{\nu}\left(T_{P_{0}}\right)+\left[1-\epsilon_{\nu}(\theta)\right] \tau_{\nu}^{\uparrow}\left(P_{0}, \theta\right) \\
& \times \int_{P_{t}}^{P_{0}} B_{\nu}\left(T_{P^{\prime}}\right) \frac{\partial \tau_{\nu}^{\downarrow}\left(P^{\prime}, \theta\right)}{\partial P^{\prime}} d P^{\prime} \\
& +\int_{P_{0}}^{P_{t}} B_{\nu}\left(T_{P^{\prime}}\right) \frac{\partial \tau_{\nu}^{\uparrow}\left(P^{\prime}, \theta\right)}{\partial P^{\prime}} d P^{\prime},
\end{aligned}
$$

where $\theta$ is the zenith angle, $B_{\nu}\left(T_{P}\right)$ is the Planck function at temperature $T_{P}$ at pressure level $P$ (with $P_{0}$ the surface pressure and $P_{t}$ the top-of-the-atmosphere pressure), $\tau_{\nu}^{\uparrow}(P, \theta)$ is the monochromatic transmittance for isotropic radiation between level of pressure $P$ and space, $\tau_{\nu}^{\downarrow}(P, \theta)$ is the monochromatic transmittance for isotropic radiation between level of pressure $P$ and surface, and $\epsilon_{\nu}(\theta)$ is the surface emissivity. Specular reflection at the surface $\left[1-\epsilon_{\nu}(\theta)\right]$ is assumed.

Equation (1) is solved by the Radiative Transfer for TOVS (RTTOV; Eyre 1991; Saunders et al. 1999) scheme for the computation of clear-sky model-equivalent satellite radiances. RTTOV also handles instruments such as Advanced TOVS or SSM/I.

\section{b. Parameterization of cloud absorption}

In the present study RTTOV is modified so that it takes cloud absorption into account in a way similar to the ECMWF operational broadband infrared radiation scheme (Morcrette 1991b). Similar work was done for HIRS/2 on a previous version of the ECMWF system but was never used routinely (Rizzi 1994).

Following the multilayer graybody approach (Washington and Williamson 1977), clouds are introduced as graybodies. Their contribution to the radiances is determined by their horizontal coverage $n^{i}$ and their emissivity $\epsilon_{\nu}^{i}$ in each vertical layer $i$ of the model. Here $\epsilon_{\nu}^{i}$ 
is derived from the cloud liquid (and/or ice) water path $l^{i}$ by the following equation:

$$
\epsilon_{\nu}^{i}=1-e^{-k_{\nu}^{i} l^{i}}
$$

where $k_{\nu}^{i}$ is the extinction coefficient at frequency $\nu$. Its value varies according to the nature (liquid or ice) of the cloud, the assumed particle size spectra, and particle temperature.

This approach enables the radiances in the presence of semitransparent cloud layers to be expressed as a linear combination of the clear-sky radiance $L_{v}^{\mathrm{Clr}}$ and of the radiances in the presence of single layered clouds treated as blackbodies, $L_{v}^{i}$. The coefficients of the linear combination are functions of the $n^{i} \mathrm{~S}$ and of the $\epsilon_{\nu}^{i} \mathrm{~S}$ and depend on the way the cloudy layers overlap. Surface reflection of the cloud downward emission is taken into account because it has a strong impact over sea for microwaves.

Various overlapping hypotheses can be used according to the vertical structure of the clouds (Morcrette and Jakob 2000). The maximum-random hypothesis, as described by Räisänen (1998) is used here. It explicitly distinguishes between the horizontal coverage and the emissivity of the cloud layers, as is done in the current operational broadband scheme.

Cloud absorption is taken into account in the infrared spectrum following Ebert and Curry (1992) for ice water and Smith and Shi (1992) for liquid water. Scattering is expected to be negligible for the wavelengths studied here (above $5 \mu \mathrm{m}$ ) at the top of the atmosphere and is therefore neglected. Consistently with the broadband radiation model, ice particle radii vary between 30 and $60 \mu \mathrm{m}$ with a temperature dependency from $\mathrm{Ou}$ and Liou (1995). Liquid particle radius is set to $10 \mu \mathrm{m}$ over land and $13 \mu \mathrm{m}$ over sea.

Cloud absorption is introduced in the microwave spectrum in the range from 1 to $200 \mathrm{GHz}$ by a direct function of frequency and liquid water/ice content following Hufford (1991) for ice and Liebe et al. (1989) for liquid water. Comparison with Mie calculations and explicit particle size distributions has shown that scattering by droplets can be neglected for all currently used microwave channels and scattering by ice particles may become significant for $\nu>60 \mathrm{GHz}$. The choice of permittivity model may be critical for liquid water at temperatures below $260 \mathrm{~K}$. Rain emission and scattering are not taken into account.

\section{c. Strategy for the MSU comparison}

Estimating the microwave land surface emissivity is difficult (Prigent et al. 1997). Over open sea, the lower values of the emissivities (around 0.5) as well as their smaller horizontal variability makes the extraction of information from the microwave data easier. As a consequence, the present study with MSU is restricted to ocean data between $60^{\circ} \mathrm{S}$ and $60^{\circ} \mathrm{N}$ only. The Ulaby et al. (1981) model provides the sea emissivity.
Among the four MSU channels, the three atmospheresounding ones (channels 2-4) are not significantly affected by clouds (except channel 2 for deep water clouds). Indeed ice water has negligible impact on the radiances around $50 \mathrm{GHz}$. Therefore results are presented here for the window channel (channel 1) as the difference between the cloud-affected radiance (either from the model or from the observation) and the clearsky radiance from the model. In the case of a perfect model, this difference is a function of liquid water and rain profiles only. In fact, uncertainties in the surface temperature and the water vapor profile degrade the accuracy of the model clear-sky radiances. However, the largest signal is due to clouds.

\section{d. Strategy for the HIRS comparison}

Understanding radiance variations in 19 channels is an evolving study. Moreover, the useful information from HIRS is contained not only in the channel brightness temperatures themselves, but also in their relative values with respect to each other.

Among the 20 channels, the present study makes use of 4 of them (channels 4-7) that are located in the $\mathrm{CO}_{2}$ band around $14 \mu \mathrm{m}$, and of 1 (channel 8) that is located in the $11-\mu \mathrm{m}$ so-called window region. First, a similar study to that for MSU is performed on HIRS-8. Then, following the work of Smith and Platt (1978), the $\mathrm{CO}_{2}-$ slicing method is used to retrieve cloud variables from these five channels. The retrieved quantities are the cloud-top pressure $P_{i}$ and the effective cloud amount $(n \epsilon)_{\nu}$ defined as

$$
L_{\nu}(\theta)=(n \epsilon)_{\nu} L_{\nu}^{i}(\theta)+\left[1-(n \epsilon)_{\nu}\right] L_{\nu}^{\mathrm{Clr}}(\theta),
$$

where $L_{v}^{i}$ is the top-of-the-atmosphere upwelling radiance emitted at frequency $\nu$ by a blackbody placed at pressure level $P_{i}$.

Assuming that $(n \epsilon)_{\nu}$ is the same for two adjacent frequencies, Eq. (3) allows for successive estimations of $P_{i}$ and of $(n \epsilon)_{v}$. Here $L_{v}^{i}$ and $L_{v}^{\mathrm{Clr}}$ are computed from a previous run of RTTOV from model temperature, absorbing gas profiles, and surface characteristics. Four pairs of channels are used from channels 4 to 7 of HIRS. The final variables are those that satisfy the radiative transfer the best. Here $(n \epsilon)_{\nu}$ is provided for the $11-\mu \mathrm{m}$ HIRS channel. As described in Wylie et al. (1994), a series of quality checks are performed. If the solution is rejected, a rough estimation is performed using Eq. (3) with $(n \epsilon)_{\nu}=1.0$ in the $11-\mu \mathrm{m}$ window channel. Retrieved cloud layers below $700 \mathrm{hPa}$ (about $3 \mathrm{~km}$ ) are most likely to correspond to this simple estimation because the $\mathrm{CO}_{2}$-slicing method is not capable of retrieving $(n \epsilon)_{v}$ in the lower troposphere.

The sources of error of the method are discussed in Menzel et al. (1992). Over open seas, the main issue appears to be multilayer cloud situations where the algorithm can only retrieve a single layer that may be below the highest transmissive cloud, depending on the 
Mid-latitudes
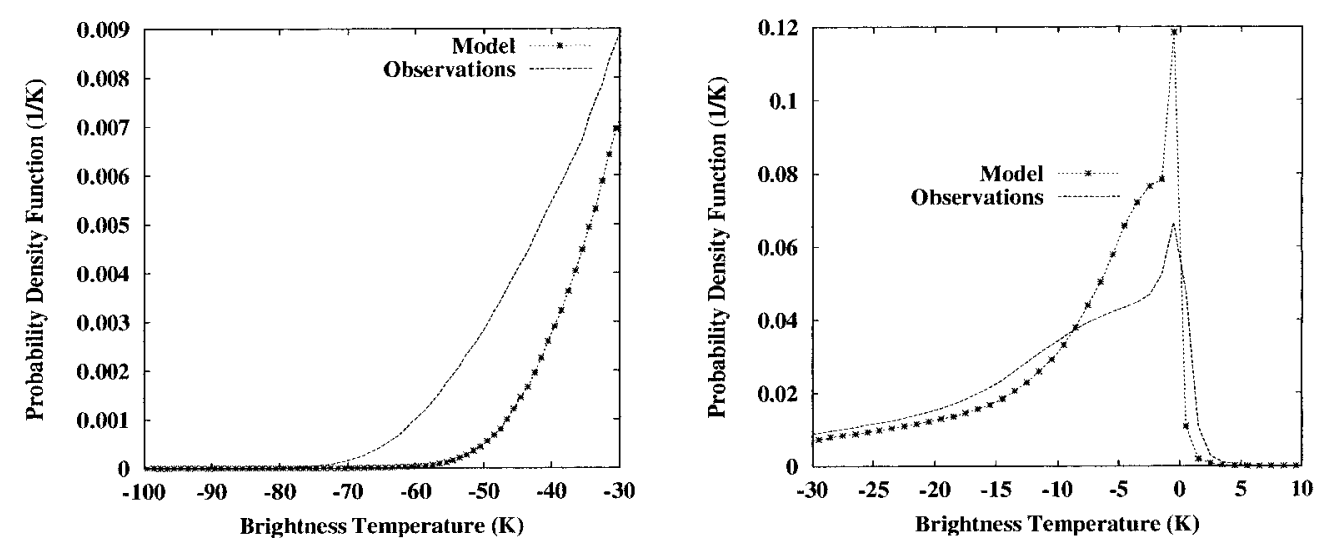

Tropical latitudes
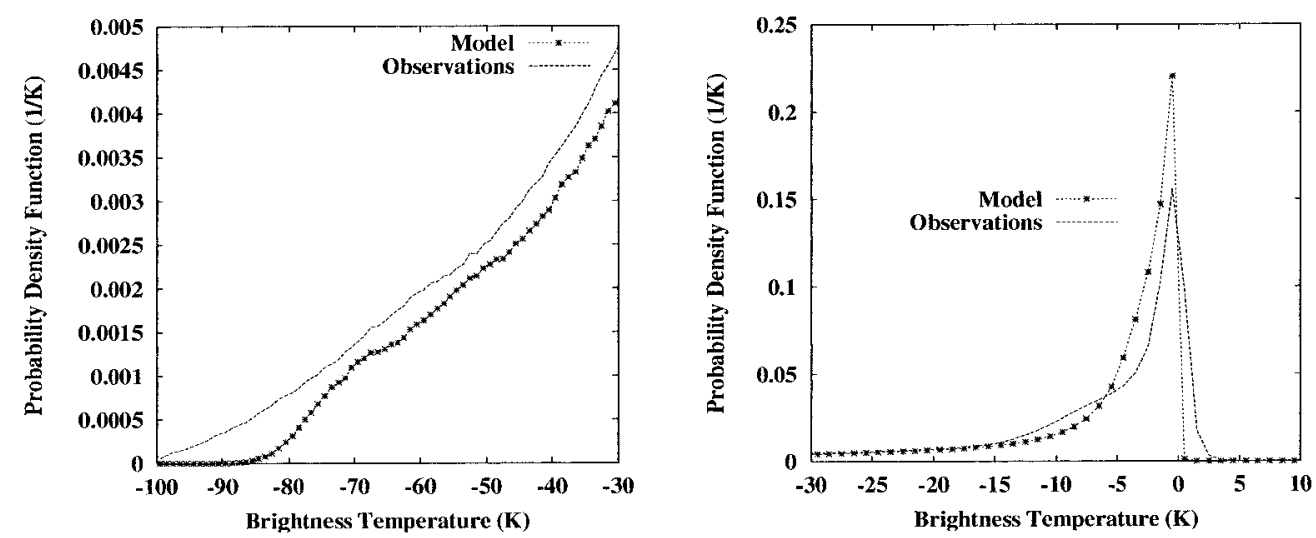

FIG. 3. Histograms of the difference between HIRS $11-\mu \mathrm{m}$ window channel cloud-affected brightness temperature, either from the model or from the observation, and the model clear-sky HIRS 11- $\mu \mathrm{m}$ brightness temperature [i.e., the difference between $\left(\mathrm{Tb}_{\text {Model }}^{\text {Full }}-\mathrm{Tb}_{\text {Model }}^{\mathrm{Clr}}\right)$ and $\left.\left(\mathrm{Tb}_{\text {Obs }}^{\text {Full }}-\mathrm{Tb}_{\text {Model }}^{\mathrm{Cl}}\right)\right]$. Because of different variation scales, the histograms are divided into two pieces. The figures cover boreal winter (DJF) over oceans.

emissivity of the clouds below. Because of reduced sensitivity of the infrared sounder in the lower troposphere, as well as possible temperature inversions close to the surface, the method is not accurate for low clouds.

The $\mathrm{CO}_{2}$-slicing technique is applied after a rough cloud detection test based on a threshold on channel 8 : a cloud is diagnosed when the observed radiance in the $11-\mu \mathrm{m}$ channel is lower than the model clear-sky radiance in the same channel by more than $1 \mathrm{~m} \mathrm{~W} \mathrm{~m}^{-2}$ $\mathrm{sr}^{-1} \mathrm{~cm}^{-1}$. This cloud detection strongly relies on the quality of the surface temperature estimation. As a consequence, the present study with HIRS is also restricted to ocean data between $60^{\circ} \mathrm{S}$ and $60^{\circ} \mathrm{N}$ only, because sea surface temperature is estimated very accurately from infrared and visible channels observations. It has also a much weaker diurnal cycle than land surface temperature. The sea surface temperature fields come from 5day averages of updated National Centers for Environmental Prediction analyses. A functional fit to the tables provided by Masuda et al. (1988) provides the infrared sea emissivity (T. J. Kleespies 1998, personal communication).

\section{MSU comparison}

Figure 1 shows the histograms of the difference between the cloud-affected MSU-1 brightness temperature $\mathrm{Tb}$ and the model clear-sky MSU-1 brightness temperature. Distinction is made between boreal winter (DJF) and summer (JJA) seasons, as well as between tropical latitudes $\left(30^{\circ} \mathrm{N}-30^{\circ} \mathrm{S}\right)$ and midlatitudes $\left(60^{\circ}-30^{\circ} \mathrm{S}\right.$ and $\left.30^{\circ}-60^{\circ} \mathrm{N}\right)$. In all cases, the histograms have the same shape. Around $0 \mathrm{~K}$ difference, about 800000 profiles are not, or nearly not, affected by hydrometeors. The other bins have much smaller numbers: about 20000. For the model, the differences are always positive because clouds are seen as warm bodies over the lowemitting sea surface. For the observations, a few profiles show negative values due to inaccurate sea surface temperature and emissivity. The good agreement between 
Mid-latitudes
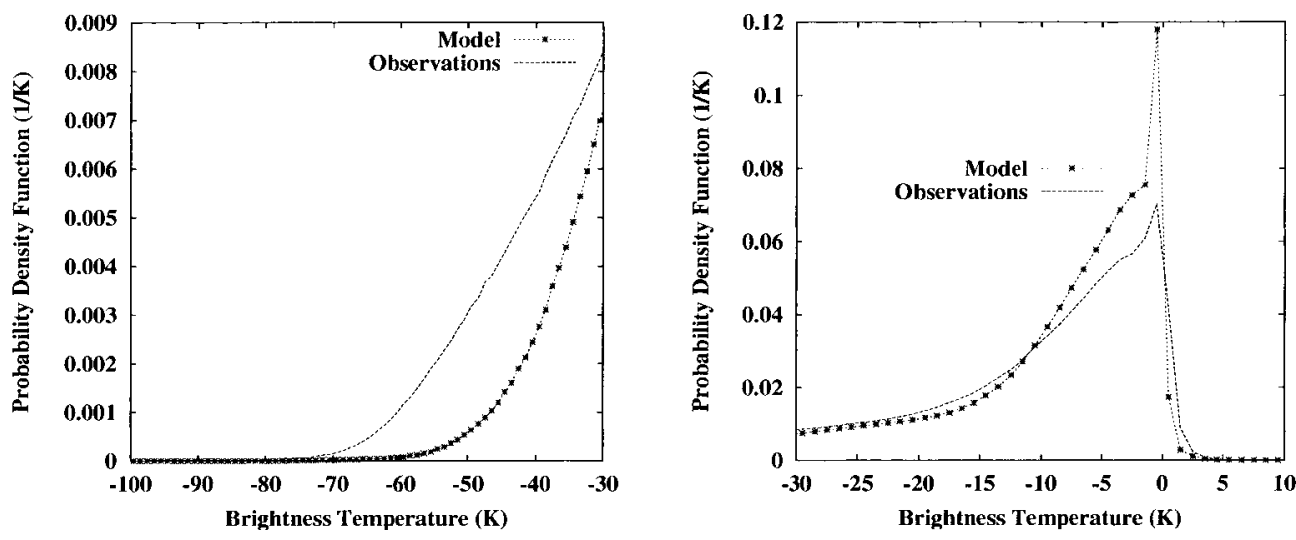

Tropical latitudes
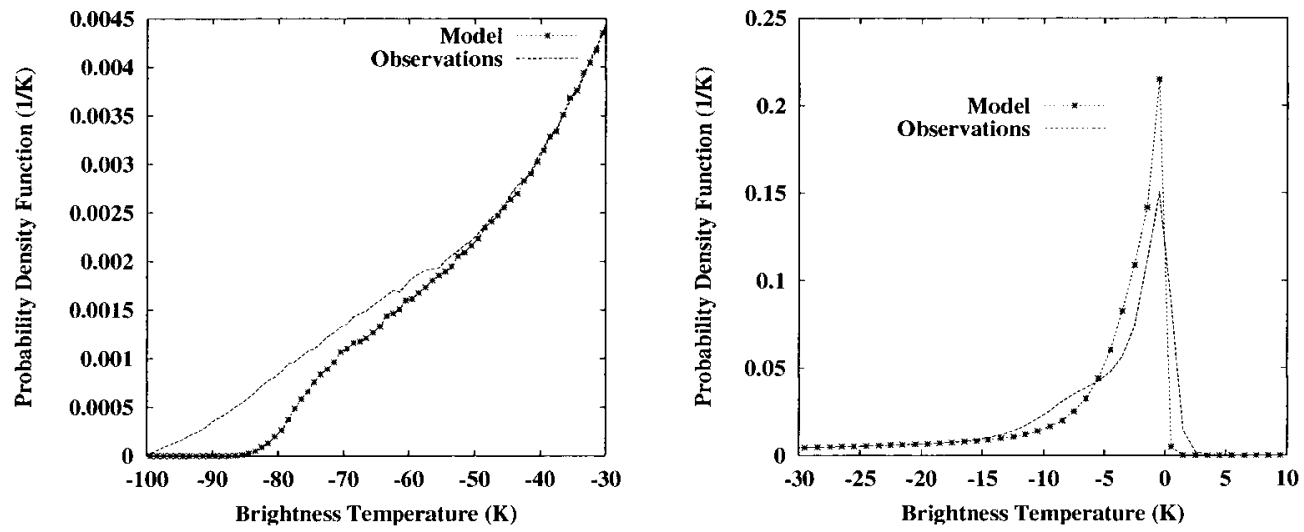

FIG. 4. Same as Fig. 3, but for the boreal summer (JJA) over oceans.

the shape of the histograms for the observations and for the model shows the general reliability of these model parameters. Moreover it indicates that the model has a correct proportion of cloud-affected profiles in each latitude band, as seen from the microwave radiometer, even though the model slightly overestimates the number of cloud-free cases. It is not possible to draw any quantitative conclusion from the shape of the positive tail, because rain absorption and scattering are not represented in the simulated radiances.

The mean value of the difference between the cloudaffected MSU-1 brightness temperature and the model clear-sky MSU-1 brightness temperature is presented in Fig. 2 for the two seasons. Few grid points (near the continents) have mean values less than $1 \mathrm{~K}$, which shows that the large amount of small instantaneous values in Fig. 1 is spread over much larger regions. Despite the limitations caused by impact of rain in the observations, a good qualitative agreement is found in the shape of the ascending-motion regions such as the intertropical convergence zone (ITCZ), the South Pacific convergence zone (SPCZ), and the storm tracks. In the descending-motion regions, the model values are significantly lower than the observation ones. In particular, in the stratocumulus regions off the west coast of the continents, the simulated microwave radiances are hardly affected by clouds. This may indicate that the model underestimates liquid water in these regions. However, an underestimation of the surface temperature and/or emissivity there would yield the same result. The study of the infrared radiances brings more information about this matter.

\section{HIRS/2 comparison}

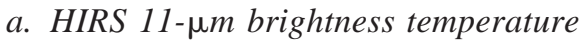

Similarly to the MSU-1 study, Figs. 3 and 4 show the histograms of the difference between the cloud-affected HIRS $11-\mu \mathrm{m}$ brightness temperature and the model clear-sky HIRS $11-\mu \mathrm{m}$ brightness temperature. The histograms peak at about $0 \mathrm{~K}$ difference. Because of the high-infrared surface emissivity, clouds usually reduce the radiances and therefore the histograms have 
(a) DJF, Observations

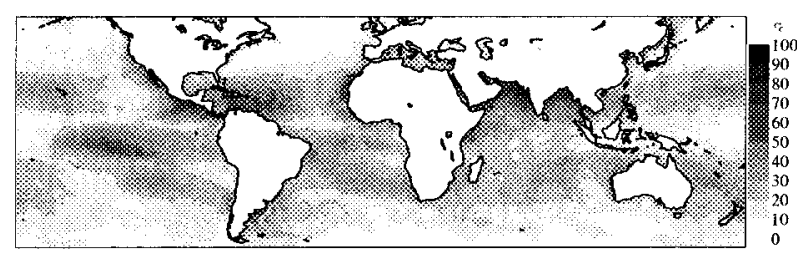

(c) JJA, Observations

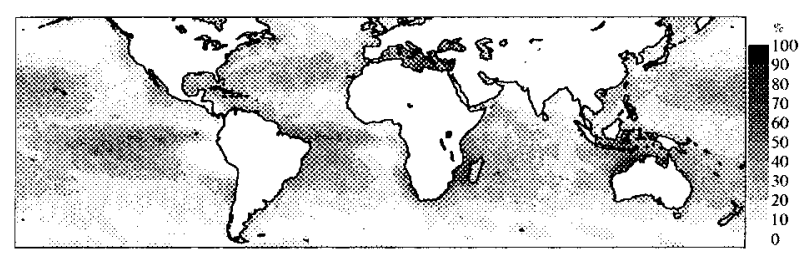

(b) DJF, Model

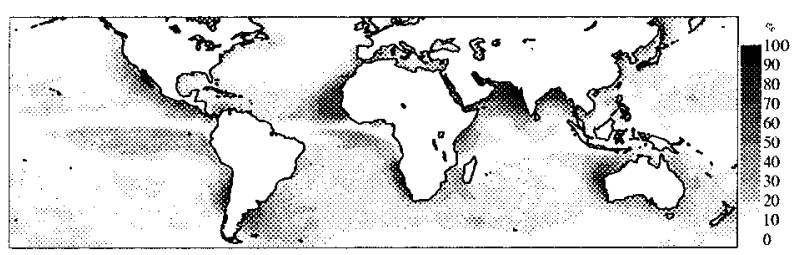

(d) JJA, Model

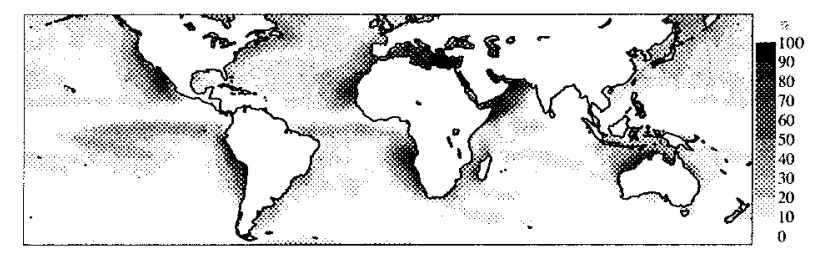

FIG. 5. Frequency of clear sky for the boreal winter season (DJF) and the boreal summer season (JJA) over the oceans (a), (c) in the observations and (b), (d) in the model.

a large negative tail. Positive values in the model differences are due to temperature inversions that may make the clouds warmer than the surface. In the observations, positive values may also come from inaccurate surface temperature and/or emissivity. The histograms have more variability with latitude than in the microwave: the large midlatitude disturbances make more cold departures in the midlatitudes than in the tropical band. It appears that the model has less large negative values, that correspond to high clouds, than the observations, in particular in the midlatitude regions.

As detailed in section $3 \mathrm{~d}$, a cloud detection based on a threshold test on the $11-\mu \mathrm{m}$ channel is used here. Figure 5 presents the frequencies of occurrence of estimated cloud-free points. With this diagnosis, the model appears to have more clouds than the observations in most regions of the globe, except in the stratocumulus regions off the west coast of the continent in both seasons, and around northern Africa in the boreal summer season only. A lack of cloudiness in these regions is consistent with the microwave results presented in section 4 . The differences in the other regions are discussed in section 6 .

\section{b. Retrieved cloud-top pressure}

The histograms of cloud-top pressures retrieved by the $\mathrm{CO}_{2}$-slicing algorithm are presented in Fig. 6. The tropical histograms are strongly influenced by the ITCZ, with cloud-top pressures between 200 and $400 \mathrm{hPa}$ as seen from space. A good agreement is found between the model and the observations. In the midlatitudes, the cloud-top pressures vary much more. Consistently with the HIRS $11-\mu \mathrm{m}$ histogram, the model appears to not correctly represent the highest radiatively active cloud tops. Also, in both latitude bands, the model has more low clouds than the observations.

\section{c. Retrieved cloud type}

A simple three-category cloud classification is defined for the clouds, based on the $\mathrm{CO}_{2}$-retrieved cloud top: high-top (cloud top above $400 \mathrm{hPa}$ ), middle-top (cloud top between 400 and $700 \mathrm{hPa}$ ), and low-top (cloud top below $700 \mathrm{hPa}$ ). The $\mathrm{CO}_{2}$-slicing method is particularly reliable for the high-top cloud category (Jin et al. 1996). The occurrence frequency of each cloud type is shown in Fig. 7 (boreal winter season) and Fig. 8 (boreal summer season). In addition, transmissive clouds are defined as high- and middle-top clouds for which the retrieved $11-\mu \mathrm{m}$ optical depth is less than 3.0 at nadir. Only high- and middle-top clouds are concerned because, as mentioned in section $3 \mathrm{~d}$, the $\mathrm{CO}_{2}$ slicing method is not able to resolve cloud amount in the lowest layers. The frequencies of transmissive clouds are presented in Fig. 9.

There is a good qualitative agreement between the model and the observation for the ITCZ structure: the seasonal variations of the narrowbanded high-top cloud structure are comparable in both, as well as its broadening in the Pacific and Indian Oceans due to large warm ocean pools, Indonesian low, and summer monsoon flows (e.g., Waliser and Gautier 1993). In the portion north of Australia, the frequencies of transmissive clouds are comparable. The model appears to produce higher frequencies of cirrus clouds in the Atlantic and the east Pacific ITCZ, where the model occurrence is about $70 \%$ in boreal summer instead of about $50 \%$ for the observations. The SPCZ is created by convergence of the southeast trade winds in the Pacific and mainly develops in the austral summer season. It is reasonably well reproduced by the model, but the transmissive clouds appear to be overrepresented. Similarly, the austral summer South Atlantic convergence zone and South Indian convergence zone as defined by Cook (2000) can 
(a) DJF, Mid-latitudes

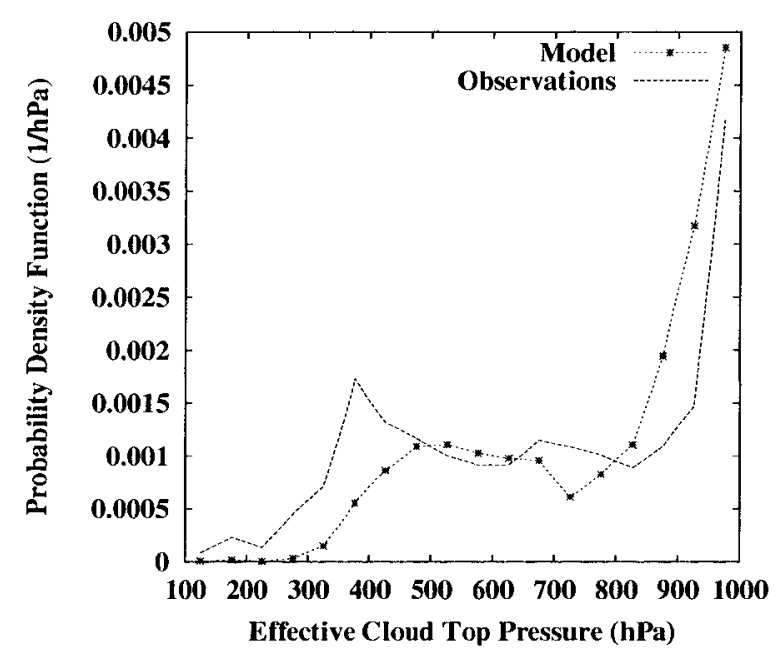

(c) JJA, Mid-latitudes

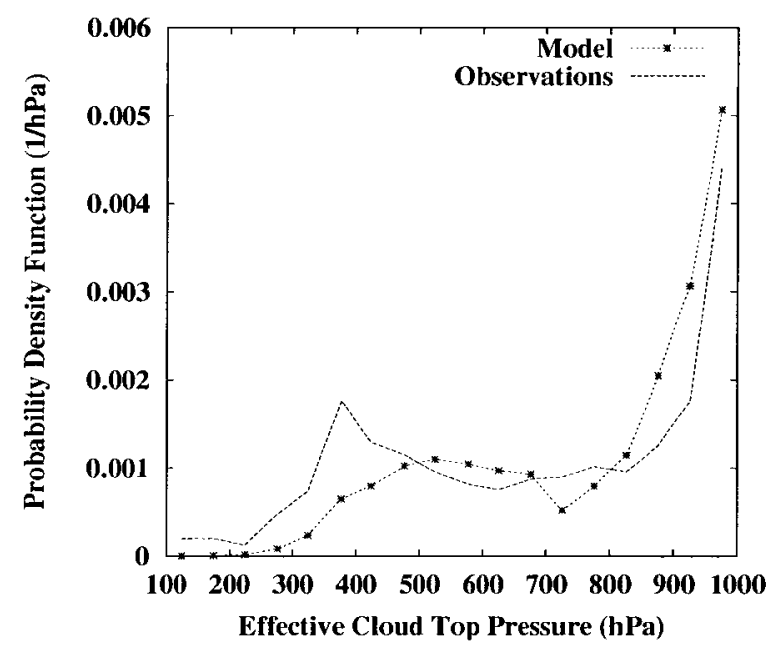

(b) DJF, Tropical latitudes

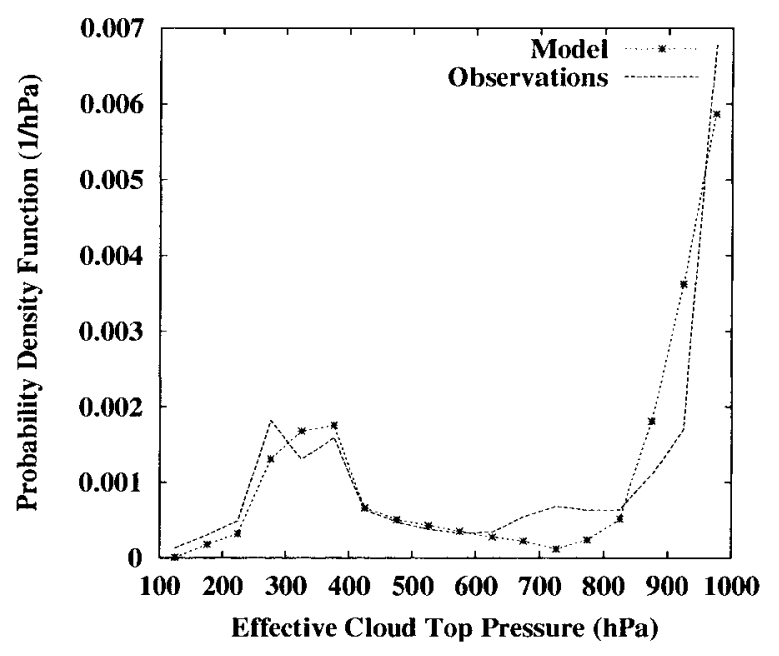

(d) JJA, Tropical latitudes

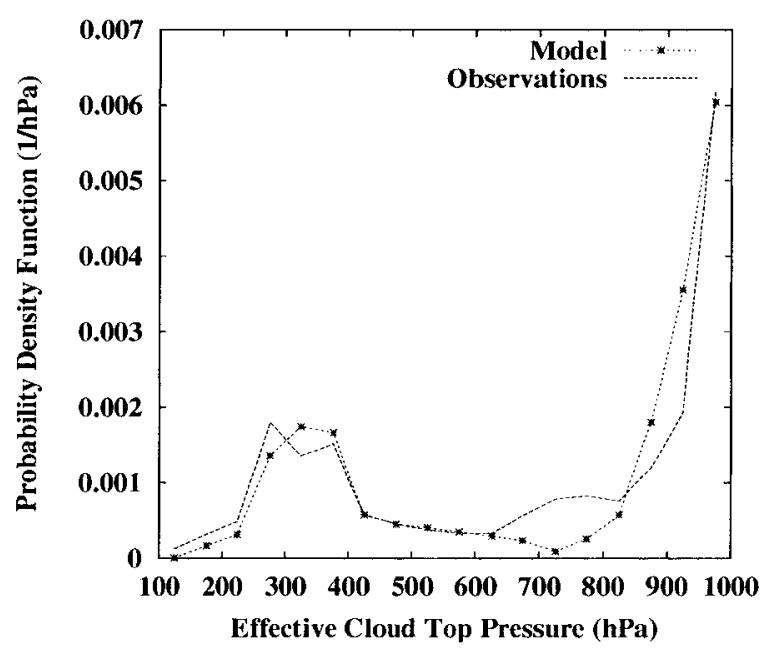

FIG. 6. Histograms of effective cloud-top pressure retrieved by the $\mathrm{CO}_{2}$-slicing method.

be identified in the model, but the frequencies of clouds in each category are different from those in the observations.

The stratus clouds off the west coast of the subtropical continents are usually associated with atmospheric subsidence over cold sea surface temperature with sharp temperature inversions in the boundary layer (e.g., Klein and Hartmann 1993). These regions are mainly cloud free in the model (Fig. 5), even though the stratus clouds are known to be dense and numerous. Surprisingly, off the Peruvian coast and California, the observations report middle-top clouds. It is likely that temperature inversions and low vertical gradients induce higher cloud tops than in reality with the $\mathrm{CO}_{2}$-slicing technique. In any case, the model poorly represents the clouds in these regions.
As the westward trade winds come closer to the ITCZ, where the sea surface is warmer, cumulus becomes the dominant cloud type (e.g., Klein and Hartmann 1993). From the observed infrared radiances, large occurrences of low clouds are depicted. The occurrences of low clouds as seen from the model radiances are even higher (about 90\%).

The storm tracks in both hemispheres have a high variability in both space and time. They appear in all three cloud categories in the observations. Consistent with the cloud-top histograms (Fig. 6), the model storm tracks have less high clouds. The model also appears to underrepresent the transmissive clouds.

As a complementary study (not shown), the main tropical and extratropical cyclones have been individually examined. No systematic deficiency could be iden- 
(a) high-top clouds, Obs.

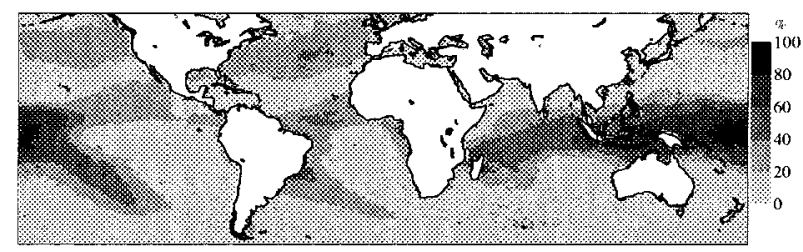

(c) middle-top clouds, Obs.

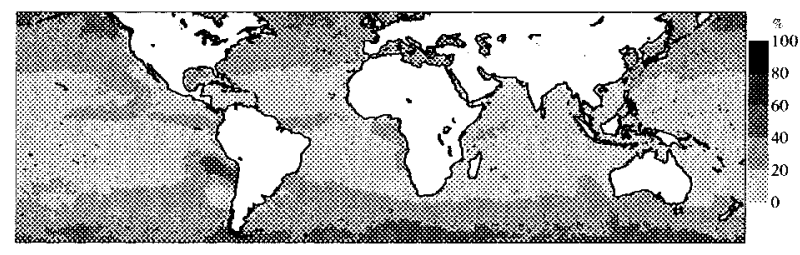

(e) low-top clouds, Obs.

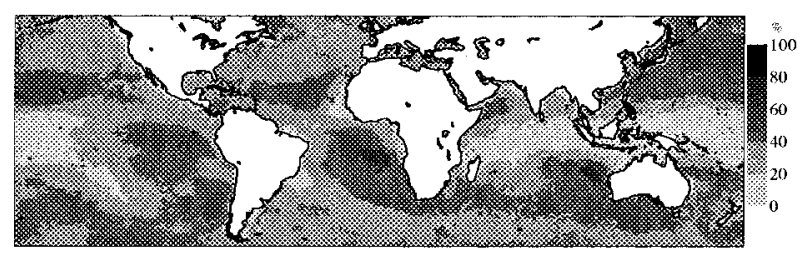

(b) high-top clouds, Model

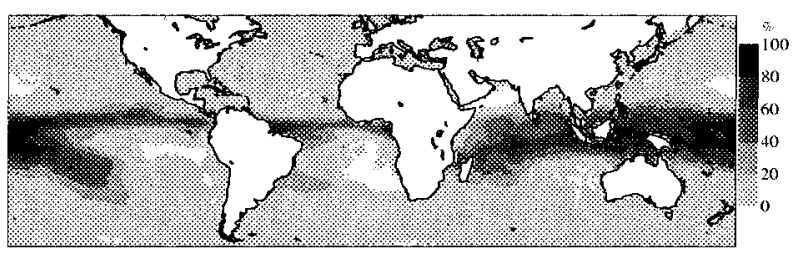

(d) middle-top clouds, Model

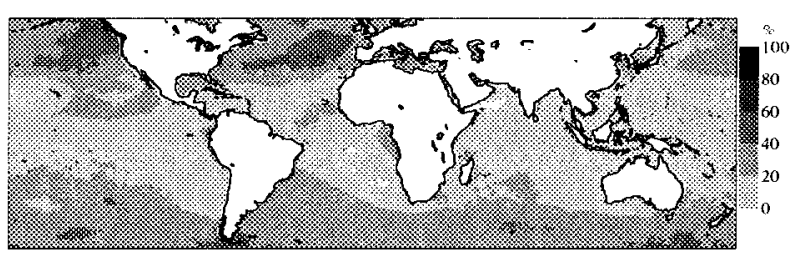

(f) low-top clouds, Model

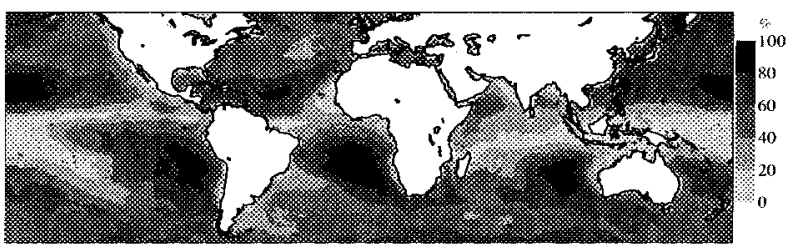

FIG. 7. Occurrence frequency of high-, middle-, and low-top clouds for the boreal winter season (DJF) over the oceans (a), (c), (e) in the observations and (b), (d), (f) in the model.

tified for the midlatitude fronts, other than the abovementioned misrepresentation of high clouds, whereas Jakob and Rizzi (1997) described the fronts as too narrow in a previous version of the model. On the other hand, tropical cyclones appear to be too spread.

\section{Discussion}

In the previous sections cloudy radiances in two spectral regions and derived cloud information as observed by the TOVS instruments were compared with those simulated using short-range forecasts from the ECMWF model in the configuration used for the ERA-40 project. Apart from documenting the method, a further aim of the study was to identify deficiencies in the representation of clouds in the ECMWF model, even though the use of the sole top-of-the-atmosphere radiation does not necessarily give a full insight into the characteristics of the model clouds. In summary of the previous sections the following features in the model have been identified:

- too little cloud-radiative effects of stratocumulus, apparent both at microwave and infrared wavelengths;

- an underestimation of the frequency of very cold brightness temperatures in both Tropics and midlatitudes;

- an overestimation of cloud-top pressure (as derived by $\mathrm{CO}_{2}$ slicing) in midlatitudes;
- an overestimation of the frequency of occurrence of low clouds except in the stratocumulus regions;

- on overestimation of the frequency of occurrence of high clouds in the ITCZ; and

- a strong underestimation of the frequency of clearsky situations, when they are defined with a simple threshold test.

The poor representation of stratocumulus clouds and their radiative effects found here is consistent with previous findings by Jakob (1999), Chevallier and Morcrette (2000), and Duynkerke and Teixeira (2001). It should be noted that although the recent increase of the vertical resolution of the ECMWF model from 31 to 60 model levels has slightly improved the simulation of this cloud type (Teixeira 1999), the model errors remain large. The correct simulation of stratocumulus by GCMs has been identified as a major problem area, and work is underway not only at ECMWF to improve their representation.

Various interesting results about the simulation of high clouds have emerged. The longwave radiative effects of high clouds seems to be underestimated, indicated by the lack of very low brightness temperatures in the model. This indicates that the model changes introduced after similar findings by Rizzi (1994), Jakob and Rizzi (1997), and Klein and Jakob (1999), such as the modifications to cloud ice settling introduced by 
(a) high-top clouds, Obs.

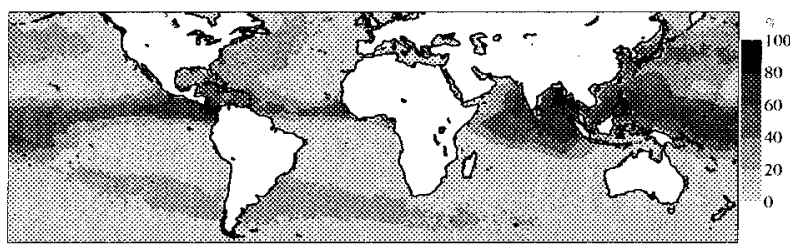

(c) middle-top clouds, Obs.

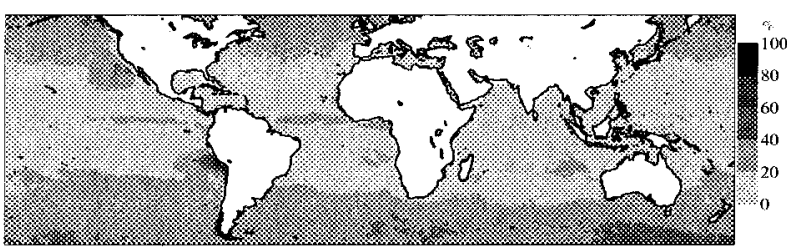

(e) low-top clouds, Obs.

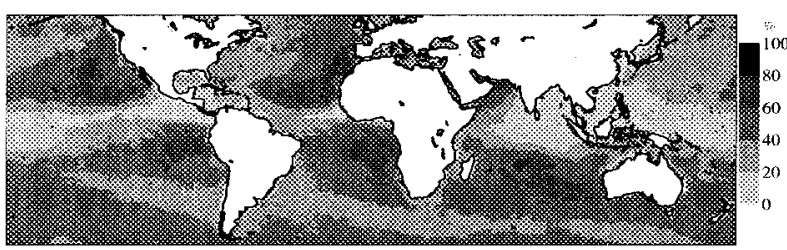

(b) high-top clouds, Model

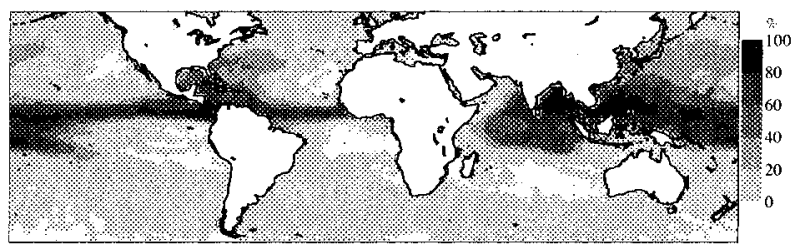

(d) middle-top clouds, Model

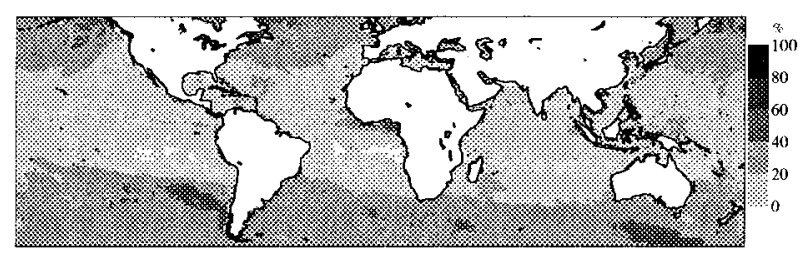

(f) low-top clouds, Model

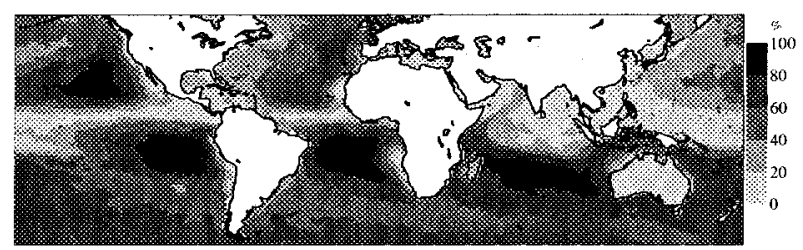

FIG. 8. Occurrence frequency of high-, middle-, and low-top clouds for the boreal summer season (JJA) over the oceans (a), (c), (e) in the observations and (b), (d), (f) in the model.

Gregory et al. (2000), have not fully solved this problem. In contrast Chevallier and Morcrette (2000) have reported an underestimation of outgoing longwave radiation (OLR) in comparison with Cloud and the Earth's Radiant Energy System measurements once the model results are averaged over several weeks. The findings here provide some insight into the reasons for this apparent contradiction. High clouds when present produce too-high brightness temperatures. However, their frequency of occurrence is overestimated by the model. Hence, the lack of radiative effect of high clouds apparent in instantaneous point-to-point comparisons (Fig. (a) DJF, Obs.

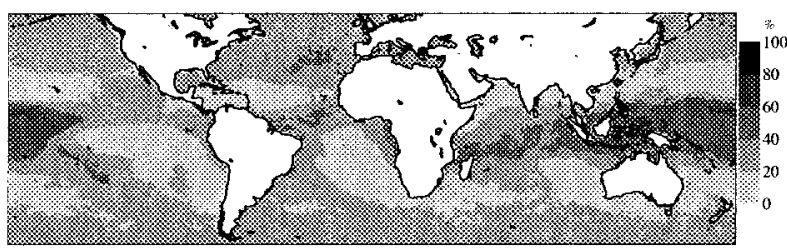

(c) JJA, Obs.

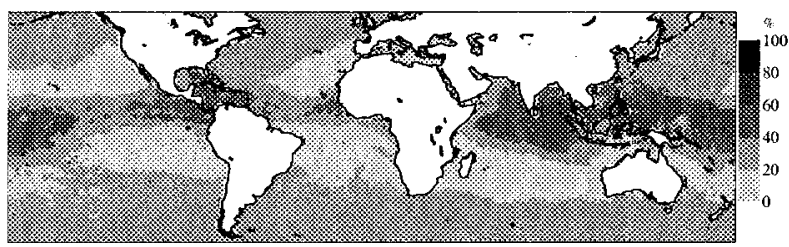

(b) DJF, Model

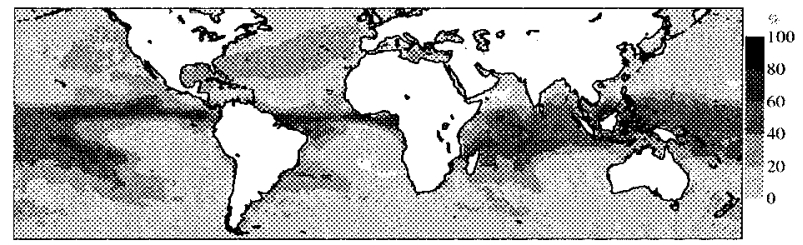

(d) JJA, Model

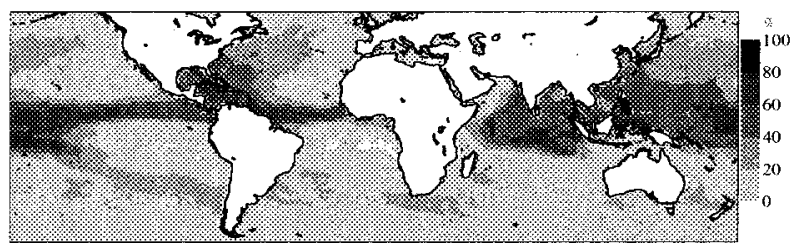

FIG. 9. Occurrence frequency of high- and middle-top transmissive clouds for the boreal winter (DJF) and summer (JJA) seasons over the oceans (a), (c) in the observations and (b), (d) in the model. 
(a) Threshold based on cloud-cover

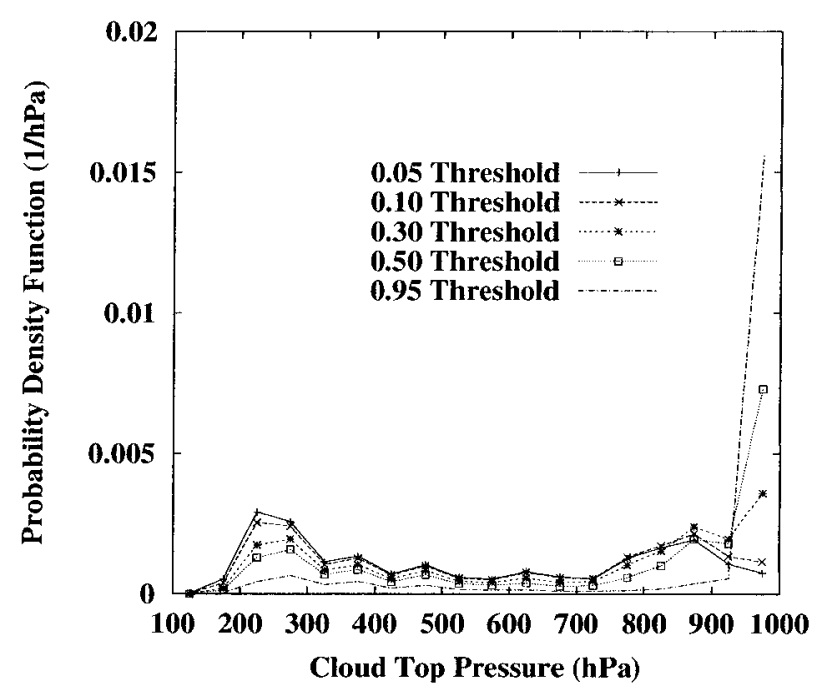

(b) Threshold based on ice water content (in $\mathrm{kg} / \mathrm{kg}$ )

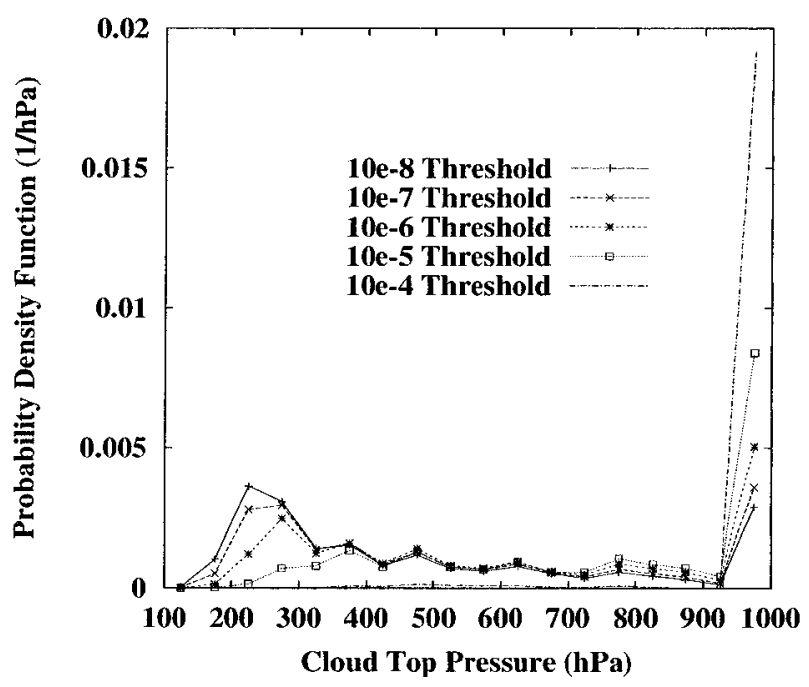

FIG. 10. Histogram of model cloud-top pressure based on various thresholds. Starting from the top of the atmosphere, the cloud top is defined as the first level that reaches the corresponding threshold. Cloud-top pressures are set to $1000 \mathrm{hPa}$ for clear-sky points. Figures represent first 10 days of Jan 1987.

3 ) is overcompensated by predicting their occurrence too frequently, leading to an overestimation of their longwave effect in longer-term averages.

OLR and infrared brightness temperature are affected by many cloud parameters, such as cloud fraction, cloud condensate content, cloud-top temperature, particle size, and overlap. It is therefore difficult to assign the shortcomings in the radiative properties or derived quantities, such as cloud-top pressure, to individual cloud parameters. An obvious way to further investigate which of the many cloud parameters is wrongly simulated by the model is to carry out sensitivity studies. However, this would require multiple integrations of the analysis system with various model versions for long periods of time, which is beyond the scope of this study. However, some insight might be gained by varying the assumptions of what is considered as a cloud in the model when estimating cloud-top pressure. An example for this is shown in Fig. 10. Here the model clouds are simply disregarded if their cloud fraction (Fig. 10a) or their cloud ice content (Fig. 10b) fall below a certain variable threshold (as indicated by the line style). The figure shows the variation of frequency distribution of cloudtop pressure in the midlatitudes when these thresholds are introduced. Note that the definitions of cloud-top pressure in this figure are much simpler than in the $\mathrm{CO}_{2}-$ slicing method. In Fig. 10a cloud-top pressure is defined by finding the pressure of the first model level seen from the top with a cloud fraction larger than the threshold value. In Fig. 10b cloud-top pressure is defined the same way but using thresholds for cloud ice content instead of cloud fraction. It is evident that when defining cloudtop pressure through cloud fraction the variation of the threshold value maintains a peak in the frequency distributions between 200 and $300 \mathrm{hPa}$. The situation is different for cloud ice content. Here using lower thresholds changes the shape of the distribution with the peak moving upward. This indicates that the most likely cause of the overestimation of effective cloud-top pressure in midlatitudes as identified in Fig. 6 is a lack of cloud ice or its radiative effects rather than an underestimation of cloud fraction. This finding is supported by the results of Klein and Jakob (1999, their Fig. 1).

Another problem identified is the apparent underestimation of the occurrence of clear-sky situations in the model. Care has to be taken interpreting that result. It is evident in Figs. 5, 7, and 8 that the largest regions with significant occurrence differences are those that usually exhibit low cloud covers such as the cumulusdominated trade wind regions. Typical values of cloud cover in both climatologies and models are on the order of $30 \%$, and individual clouds are at most a few kilometres in horizontal extent. Because the model resolution (about $60 \mathrm{~km}$ ) is lower than the satellite one (about $20 \mathrm{~km}$ close to nadir), higher cloud frequencies are expected in the model.

As illustrated here, although not assimilated, cloudyaffected TOVS data are a key element of the monitoring of the ECMWF 40-yr reanalysis. As a consequence, the model radiances and the $\mathrm{CO}_{2}$-derived cloud variables from the model and from the HIRS observations will be part of the archive for the period following the first TOVS launch in 1978. The cloud variables derived from the observations will be a product of the reanalysis of direct climatological relevance. In addition they will help to validate the interannual variations of the model. The deficiencies identified here appear to be major challenges for modelers. Work is currently under way at 
ECMWF to remedy some of the problems highlighted here, in particular in the area of boundary layer clouds.

Compositing and case studies (e.g., Klein and Jakob 1999) will be used to further refine the analysis of the model deficiencies in ERA-40 as well as in the operational analyses, with TOVS, SSM/I, and geostationary imagery. Last, ongoing work aims at an objective feedback from the observed differences on the model through variational data assimilation of the cloud-affected radiances (Chevallier et al. 2000; Janisková et al. 2000).

Acknowledgments. The ERA-40 project is managed by S. Uppala. D. P. Wylie and P. Menzel provided the initial version of the $\mathrm{CO}_{2}$-slicing subroutine. The authors are grateful to J.-J. Morcrette for fruitful discussions about the cloud absorption parameterization. The help of E. Andersson and S. Saarinen in introducing the cloud-affected radiance computation in the ECMWF forecast system was greatly appreciated. This work was done at the Satellite Application Facility on Numerical Weather Prediction, which is cosponsored by Eumetsat. J.-F. Mahfouf, A. Simmons, and D. Wylie helped to improve the initial manuscript.

\section{REFERENCES}

Andersson, E., and Coauthors, 1998: The ECMWF implementation of three-dimensional variational assimilation (3D-Var). III: Experimental results. Quart. J. Roy. Meteor. Soc., 124, 1831-1860.

Baum, B. A., P. F. Soulen, K. I. Strabala, M. D. King, S. A. Ackerman, W. P. Menzel, and P. Yang, 2000: Remote sensing of cloud properties using MODIS airborne simulator imagery during SUCCESS. 2. Cloud thermodynamic phase. J. Geophys. Res., 105, $11781-11792$.

Bony, S., Y. Sud, K. M. Lau, J. Susskind, and S. Saha, 1997: Comparison and satellite assessment of NASA/DAO and NCEPNCAR reanalyses over tropical ocean: Atmospheric hydrology and radiation. J. Climate, 10, 1441-1462.

Chevallier, F., and J.-J. Morcrette, 2000: Comparison of model fluxes with surface and top-of-the-atmosphere observations. Mon. Wea. Rev., 128, 3839-3852.

_ - P. Bauer, G. Kelly, J.-F. Mahfouf, C. Jakob, and T. McNally, 2000: Requirements for the assimilation of cloudy radiances. Proc. ECMWF/Euro TRMM Workshop on Assimilation of Clouds and Precipitation, Reading, United Kingdom, ECMWF, in press.

Cook, K. H., 2000: The South Indian Convergance Zone and interannual rainfall variability over Southern Africa. J. Climate, 13, 3789-3804

Courtier, P., and Coauthors, 1998: The ECMWF implementation of three dimensional variational assimilation (3D-Var). Part I: Formulation. Quart. J. Roy. Meteor. Soc., 124, 1783-1808.

Duynkerke, P. G., and J. Teixeira, 2001: Comparison of the ECMWF reanalysis with FIRE I observations: Diurnal variation of marine stratocumulus. J. Climate, 14, 1466-1478.

Ebert, E. E., and J. A. Curry, 1992: A parameterization of cirrus cloud optical properties for climate models. J. Geophys. Res. 97, 3831-3836.

Eyre, J. R., 1991: A fast radiative transfer model for satellite sounding systems. ECMWF Tech. Memo. No. 176, ECMWF, 28 pp.

Fouquart, Y., and B. Bonnel, 1980: Computation of solar heating of the Earth's atmosphere: A new parameterization. Beitr. Phys. Atmos., 53, 35-62.

Gregory, D., J.-J. Morcrette, C. Jakob, A. C. M. Beljaars, and T Stockdale, 2000: Revision of convection, radiation and cloud schemes in the ECMWF Integrated Forecasting System. Quart. J. Roy. Meteor. Soc., 126, 1685-1710.

Harris, B. A., and G. Kelly, 2001: A satellite radiance bias correction scheme for radiance assimilation. Quart. J. Roy. Meteor. Soc., 127, 1453-1468.

Hortal, M., 1999: The development and testing of a new two-timelevel semi-Lagrangian scheme (SETTLS) in the ECMWF forecast model. ECMWF Tech. Memo. No. 292, 17 pp.

Hufford, G., 1991: A model for the complex permittivity of ice. Int. J. Infrar. Millimeter Waves, 12, 677-681.

Jakob, C., 1994: The impact of the new cloud scheme on ECMWF's Integrated Forecasting System (IFS). Proc. ECMWF/GEWEX Workshop on Modelling, Validation and Assimilation of Clouds, Reading, United Kingdom, ECMWF, 277-294.

, 1999: Cloud cover in the ECMWF reanalysis. J. Climate, 12, 947-959.

_ 2000: The representation of cloud cover in atmospheric general circulation models. Ph.D. thesis, Ludwig-Maximilians-Universität München, Munich, Germany, 193 pp.

__ , and R. Rizzi, 1997: Evaluation of model OLR in cloudy regions using TOVS-1B data. Proc. Int. TOVS Study Conf., Igls, Austria, Int. TOVS Working Group, 197-206.

— , and S. A. Klein, 2000: A parameterization of the effects of cloud and precipitation overlap for use in general-circulation models. Quart. J. Roy. Meteor. Soc., 126, 2525-2544.

—_, and Coauthors, 2000: The IFS cycle CY21r4 made operational in October 1999. ECMWF Newsl., 87, 2-9.

Janisková, M., J.-F. Mahfouf, F. Chevallier, and J.-J. Morcrette, 2000: Linearized physics for the assimilation of cloud properties. Proc. ECMWF/EuroTRMM Workshop on Assimilation of Clouds and Precipitation, Reading, United Kingdom, ECMWF, in press.

Jin, Y., W. B. Rossow, and D. P. Wylie, 1996: Comparison of the climatologies of high-level clouds from HIRS and ISCCP. $J$. Climate, 9, 2850-2879.

Kidwell, K. B., 1998: NOAA polar orbiter user's guide. Tech. Report, NOAA/NESDIS, $486 \mathrm{pp}$.

Klein, S. A., and D. L. Hartmann, 1993: The seasonal cycle of low stratiform clouds. J. Climate, 6, 1587-1606.

— clouds simulated by the ECMWF model. Mon. Wea. Rev., 127, 2514-2531.

Le Treut, H., and Z. Li, 1988: Using Meteosat data to validate a prognostic cloud generation model. Atmos. Res., 21, 273-292.

Liebe, H. J., T. Manabe, and G. A. Hufford, 1989: Millimeter wave attenuation and delay rates due to fog/cloud conditions. IEEE Trans. Antennas Propag., 37, 1617-1623.

Masuda, K., T. Takashima, and Y. Takayama, 1988: Emissivity of pure and sea waters for the model sea surface in the infrared window regions. Remote Sens. Environ., 24, 313-329.

McMillin, L. M., and C. Dean, 1982: Evaluation of a new operational technique for producing clear radiance. J. Appl. Meteor., 21, $1005-1014$

Menzel, W. P., D. P. Wylie, and K. I. Strabala, 1992: Seasonal and diurnal changes in cirrus clouds as seen in four years of observations with the VAS. J. Appl. Meteor., 31, 370-385.

Mlawer, E. J., S. J. Taubman, P. D. Brown, M. J. Iacono, and S. A. Clough, 1997: Radiative transfer for inhomogeneous atmospheres: RRTM, a validated correlated-k model for the longwave. J. Geophys. Res., 102, 16 663-16 682.

Morcrette, J.-J., 1991a: Evaluation of model-generated cloudiness: Satellite observed and model-generated diurnal variability and brightness temperature. Mon. Wea. Rev., 119, 1205-1224.

$\ldots$, 1991b: Radiation and cloud radiative properties in the European Centre for Medium-Range Weather Forecasts forecasting system. J. Geophys. Res., 96, 9121-9132.

— changes in cloud overlap assumption. Mon. Wea. Rev., 128, 1707-1732.

Munro, R., G. Kelly, and R. Saunders, 2000: Assimilation of Meteosat 
Radiance Data within the 4DVAR System at ECMWF. EUMETSAT/ECMWF Fellowship Programme Rep. 8, 41 pp.

Ou, S., and K. Liou, 1995: Ice microphysics and climate temperature feedback. Atmos. Res., 35, 127-138.

Price, J. C., 1991: Timing of NOAA afternoon passes. Int. J. Remote Sens., 12, 193-198.

Prigent, C., W. B. Rossow, and E. Matthews, 1997: Microwave land surface emissivities estimated from SSM/I observations. J. Geophys. Res., 102, $21867-21890$.

Rabier, F., A. McNally, E. Andersson, P. Courtier, P. Unden, J. Eyre, A. Hollingsworth, and F. Bouttier, 1998: The ECMWF implementation of three dimensional variational assimilation (3DVar). Part II: Structure functions. Quart. J. Roy. Meteor. Soc., 124, 1809-1829.

Räisänen, P., 1998: Effective longwave cloud fraction and maximumrandom overlap clouds-A problem and a solution. Mon. Wea. Rev., 126, 3336-3340.

Rizzi, 1994: Raw HIRS/2 radiances and model simulations in the presence of clouds. ECMWF Tech. Memo. No. 73, 29 pp.

Rossow, W. B., and R. A. Schiffer, 1991: ISCCP cloud data products. Bull. Amer. Meteor. Soc., 72, 2-20.

Saunders, R., M. Matricardi, and P. Brunel, 1999: An improved fast radiative transfer model for assimilation of satellite radiance observations. Quart. J. Roy. Meteor. Soc., 125, 1407-1425.

Shah, K. P., and D. Rind, 1995: Use of microwave brightness temperatures with a general circulation model. J. Geophys. Res., 100, 13 841-13 874.

Simmons, A. J., and J. K. Gibson, Eds., 2000: The ERA-40 project plan. ERA-40 Project Rep. Series No. 1, 62 pp.

Smith, E. A., and L. Shi, 1992: Surface forcing of the infrared cooling profile over the Tibetan Plateau. Part I: Influence of relative longwave radiative heating at high altitude. J. Atmos. Sci., 49, $805-822$.

Smith, W. L., and C. M. R. Platt, 1978: Intercomparison of radiosonde, ground-based laser, and satellite-deduced cloud heights. J. Appl. Meteor., 17, 1796-1802.

Stubenrauch, C. J., W. B. Rossow, F. Chéruy, A. Chédin, and N. A. Scott, 1999: Clouds as seen by satellite sounders (3I) and images (ISCCP). Part I: Evaluation of cloud parameters. J. Climate, 12, 2189-2213.

Teixeira, J., 1999: The impact of increased boundary layer resolution on the ECMWF forecast system. ECMWF Tech. Memo. 268, 55 pp.

Tiedtke, M., 1993: Representation of clouds in large-scale models. Mon. Wea. Rev., 121, 3040-3061.

Ulaby, F. T., R. K. Moore, and A. K. Fung, 1981: Microwave Remote Sensing: Active and Passive. Vol. I. Artech House, 456 pp.

van den Hurk, B. J. J. M., P. Viterbo, A. C. M. Beljaars, and A. K. Betts, 2000: Offline validation of the ERA40 surface scheme. ECMWF Tech. Memo. No. 295, 42 pp.

Waliser, D. E., and C. Gautier, 1993: A satellite-derived climatology of the ITCZ. J. Climate, 6, 2162-2174.

Washington, W. M., and D. L. Williamson, 1977: A description of the NCAR GCM's in general circulation models of the atmosphere. Method in Computational Physics, J. Chang, Ed., Vol. 17, Academic Press, 11 100-17 002.

Wylie, D. P., and W. P. Menzel, 1999: Eight years of high cloud statistics using HIRS. J. Climate, 12, 170-184.

- - H. M. Woolf, and K. I. Strabala, 1994: Four years of global cirrus cloud statistics using HIRS. J. Climate, 7, 19721986. 